\title{
Non-pharmacological intervention for neonatal pain control
}

\author{
Paola Lago ${ }^{1 *}$, Elisabetta Garetti ${ }^{2}$, Anna Pirelli $^{3}$, Daniele Merazzi ${ }^{4}$, Carlo V Bellieni ${ }^{5}$, Patrizia Savant Levet ${ }^{6}$, \\ Luisa Pieragostini ${ }^{7}$, Gina Ancora ${ }^{8}$ \\ From XX National Congress of the Italian Society of Neonatology \\ Rome, Italy. 9-11 October 2014
}

\section{Background}

Acute pain and distress during medical procedures are commonplace in newborn admitted to Intensive Care Unit and can have detrimental effects, if uncontrolled.

Accumulating evidence suggests that neonate, as older children, could benefice of non pharmacological interventions (NPIs) to relive mild to moderate pain, anxiety and discomfort from minor invasive procedures. [1] These therapies include nonnutritive sucking (NNS) both with and without sucrose, swaddling, positioning, facilitated tucking (FT), kangaroo care or skin to skin contact (KMC), multi-sensorial stimulation (SS) and music therapy.

\section{Material and methods}

To assess efficacy of NPIs for acute procedural pain in neonate, a literature search covered the period 2000-2014 via Medline and Cochrane Library database, was undertaken. Inclusion criteria were preterm and newborn, involved in randomized controlled or crossover trial. Pain reactivity was described in term of physiological parameters (heart rate, oxygen saturation) behavioral indicators (duration of first cry and total crying time) and validated unidimensional, multidimensional and/or composite pain scores as PIPP, NIPS, DAN, NFCS etc. Two independent reviewers extracted data and methodological quality was assessed, according with GRADE system.

\section{Results}

Nineteen Randomized Controlled Trials and twelve metaanalysis and systematic reviews were taken in consideration. The efficacy of NPIs in reliving pain and distress

\footnotetext{
* Correspondence: lago@pediatria.unipd.it

'Woman's and Child's Health Department, Azienda Ospedaliera-University of Padova, Padova, Italy

Full list of author information is available at the end of the article
}

from skin-breaking procedures has been demonstrated mostly in heel prick and venipuncture. (Table 1)

There are sufficient evidence that supports efficacy in reducing pain-relating behaviors for NNS, swaddling and FT in preterm and term neonates. [1] KMC appears to be effective, as measured by composite pain score including physiological and behavioral indicators and safe for single painful procedures, alone or combined with other NPIs. [2] Small volumes of $24 \%$ sucrose with or without NNS reduced efficiently behavioral expressions of pain and crying time, as well as PIPP scores. [3] Also expressed human milk or breastfeeding, if available, should be used to alleviate procedural pain [4], as well as $20-30 \%$ glucose [5]. SS is more effective than glucose and sucking, but there are no studies comparing SS and standard sucrose $24 \%$ and NNS with pacifier, which actually is the standard of care for heel lance. [6]

Limited evidence suggests that Music Therapy may be beneficial primarily for measures of behavior and pain, however the heterogeneity of the study preclude definitive conclusions. [7]

\section{Conclusions}

As the efficacy of the majority of NPIs is clearly demonstrated in preterm and neonates, they should be considered for inclusion in a graduated multidisciplinary algorithm for neonatal pain management.

\footnotetext{
Authors' details

${ }^{1}$ Woman's and Child's Health Department, Azienda Ospedaliera-University of Padova, Padova, Italy. 'Dept of Pediatrics, Azienda Ospedaliero-UniversitariaPoliclinico di Modena, Italy. ${ }^{3}$ San Gerardo Hospital, Monza, Italy. ${ }^{4}$ Dept of Women's and Children's Health, Valduce Hospital, Como, Italy. ${ }^{5}$ Dept of Pediatrics, University Hospital, Siena, Italy. ${ }^{6}$ Mother's and Child's Health Department, Maria Vittoria Hospital, Torino, Italy. ${ }^{7}$ San Filippo Neri Hospital, Roma, Italy. ${ }^{8}$ Azienda Ospedaliera Rimini, Italy.
} 
Table 1 Efficacy of environmental, behavioral and non-pharmacological strategies on pain reactivity in newborn.

\begin{tabular}{|c|c|c|c|c|}
\hline \multirow[t]{2}{*}{ Behavioral, cognitive and contextual interventions } & \multicolumn{3}{|c|}{ Level of evidence } & \multirow{2}{*}{$\begin{array}{l}\text { Grade of } \\
\text { Recommendation }\end{array}$} \\
\hline & $\begin{array}{l}\text { Heel } \\
\text { Prick }\end{array}$ & Venipuncture & Other & \\
\hline $\begin{array}{l}\text { Non-nutritive sucking (NNS): placing a pacifier or non-lactating nipple in an infant's mouth } \\
\text { to promote sucking behavior with no breast or formula milk to provide nourishment. }\end{array}$ & 1 & 1 & - & Strong \\
\hline Facilitated tucking: holding the arms and legs in a flexed position & 1 & 1 & $\begin{array}{c}3 \mathrm{ET} \\
\text { Suctioning }\end{array}$ & Strong \\
\hline Swaddling: wrapping securely the neonate in a sheet/blanket & 1 & 1 & - & Strong \\
\hline Positioning: laying the neonate supine & 3 & 3 & - & Weak \\
\hline Maternal touching and holding: cradling the baby in the mother's arms & 3 & 3 & - & Weak \\
\hline Environmental care: controlling/ reducing light and noise, clustering care etc. & 3 & 3 & - & Weak \\
\hline $\begin{array}{l}\text { Individualized developmental care e.g. limiting environmental stimuli, lateral positioning, } \\
\text { using supportive bedding, monitoring behavioural clues, respecting circadian rhythms }\end{array}$ & - & - & $\begin{array}{c}3 \text { ROP } \\
\text { screening }\end{array}$ & Weak \\
\hline $\begin{array}{l}\text { Skin to skin or Kangaroo Mother Care an infants is placed on their care-giver's bare chest } \\
\text { during a painful procedure or for soothing after a painful procedure }\end{array}$ & 1 & 2 & $2 \mathrm{IM}$ & Strong \\
\hline $\begin{array}{l}\text { Sensorial saturation: multiple sensorial stimulation at gustatory, auditory, olfactory and } \\
\text { tactile level }\end{array}$ & 1 & - & - & Strong \\
\hline Music therapy: music with intrauterine sounds or instrumental music in association with NNS & 3 & 3 & - & Weak \\
\hline $\begin{array}{l}\text { Sucrose } 24 \% \text { : in dose of } 0.1-0.3 \mathrm{ml} \text { orally } 2 \text { minutes before the procedure in preterm infants } \\
\text { and } 1-2 \mathrm{ml} \text { in term infants. }\end{array}$ & 1 & 1 & - & Strong \\
\hline Breastfeeding or expressed human milk & 1 & 1 & - & Strong \\
\hline Glucose solutions $\mathbf{2 0 - 3 0 \%}$ in dose of $1-2 \mathrm{ml}$ orally 2 minutes before the procedure. & 1 & 1 & - & Strong \\
\hline
\end{tabular}

ET suctioning= endotracheal suctioning, $\mathrm{ROP}=$ retinopathy of prematurity $\mathrm{IM}=$ intramuscular injection Legend

1. Sufficient evidence supports efficacy for reducing pain-related behaviors (support of two or more trials)

2. Limited evidence suggests efficacy for reducing pain-related behaviors (e.g. support of 1 trial or heterogeneity among trial)

3. Limited evidence suggests inefficacy for reducing pain-related behaviors (e.g. support of 1 trial or heterogeneity among trial)

4. Sufficient evidence supports inefficacy for reducing pain-related behaviors ( support of two or more trial)

Published: 9 October 2014

\section{References}

1. Pillar Riddell RR, Racine NM, Turcotte K, Uman LS, Horton RE, Din Osmun L, Ahola Kohut S, Hillgrove Stuart J, Stevens B, Gerwitz-Sten A: Nonpharmacological management of infant and young child procedural pain. Cochrane Database of Systematic Reviews 2011, , 10: CD006275.

2. Johnston C, Campbell-Yeo M, Fernandes A, Inglis D, Streiner D, Zee R: Skinto-skin for procedural pain in neonates. Cochrane Database of Systematic Reviews 2014, 1: CD008435.

3. Stevens B, Yamada J, Lee GY, Ohlsson A: Sucrose for analgesia in newborn infants undergoing painful procedures. Cochrane Database of Systematic Reviews 2013, 1: CD001069.

4. Shah PS, Herbozo C, Aliwalas LL, Shah VS: Breastfeeding or breast milk for procedural pain in neonates. Cochrane Database of Systematic Reviews 2013, , 12: CD004950.

5. Bueno M, Yamada J, Harrison D, Khan S, Ohlsson A, Adams-Webber T, Beyene J, Stevens B: A systematic review and meta-analysis of nonsucrose sweet solutions for pain relief in neonates. Pain Res Manag 2013, 18:153-161.

6. Bellieni CV, Bagnoli F, Perrone S, Nenci A, Cordelli DM, Fusi M, Ceccarelli s, Buonocore G: Effect of multisensory stimulation on analgesia in term neonates: a randomized controlled trial. Pediatr Res 2002, 51:460-3.

7. Harling L, Shaik MS, Tjosvold L, Leich R, Liang Y, Kumar M: Music for medical indications in the neonatal period: a systematic review of randomized controlled trials. Arch Dis Child Fetal Neonatal Ed 2009, 94: F349-354.

\section{Submit your next manuscript to BioMed Central and take full advantage of:}

- Convenient online submission

- Thorough peer review

- No space constraints or color figure charges

- Immediate publication on acceptance

- Inclusion in PubMed, CAS, Scopus and Google Scholar

- Research which is freely available for redistribution 